\title{
Correction to: Stimulus familiarity improves consolidation of visual working memory representations
}

\section{Lisa Durrance Blalock ${ }^{1}$}

Published online: 15 February 2022

(c) The Psychonomic Society, Inc. 2022

\section{Correction to: Atten Percept Psychophys} https://doi.org/10.3758/s13414-014-0823-z

The typesetter repeated the Figure 2 image above the caption for Figure 3. The original article has been corrected.

Publisher's note Springer Nature remains neutral with regard to jurisdictional claims in published maps and institutional affiliations.

The original article can be found online at https://doi.org/10.3758/ s13414-014-0823-z.

Lisa Durrance Blalock

lblalock@uwf.edu

1 Department of Psychology, University of West Florida, 11000 University Parkway, Pensacola, FL 32514, USA 